Corresponding authors: dg2875@cumc.columbia.edu, vandana.shashi@duke.edu

(c) 2015 Shashi et al. This article is distributed under the terms of the Creative Commons

Attribution-NonCommercial License, which permits reuse and redistribution, except for commercial purposes, provided that the original author and source are credited.

Ontology terms: drooling, gait imbalance, neurodegeneration, seesaw nystagmus, upper motor neuron abnormality

Published by Cold Spring Harbor Laboratory Press

doi: $10.1101 /$ mcs.a000265

\section{Sustained therapeutic response to riboflavin in a child with a progressive neurological condition, diagnosed by whole-exome sequencing}

\author{
Vandana Shashi, ${ }^{1,8}$ Slavé Petrovski, ${ }^{2,3,8}$ Kelly Schoch, ${ }^{1}$ Rebecca Crimian, ${ }^{1}$ \\ Laura E. Case, ${ }^{4}$ Roha Khalid, ${ }^{5}$ Maysantoine A. El-Dairi, ${ }^{6}$ Yong-Hui Jiang, ${ }^{1,7}$ \\ Mohamad A. Mikati, ${ }^{5}$ and David B. Goldstein ${ }^{2}$

\begin{abstract}
${ }^{1}$ Department of Pediatrics, Division of Medical Genetics Duke University School of Medicine, Durham, North Carolina 27710, USA $^{2}$ Institute for Genomic Medicine, Columbia University, New York, New York 10032, USA; ${ }^{3}$ Department of Medicine, The University of Melbourne, Austin Health and Royal Melbourne Hospital, Melbourne, 3050 Victoria, Australia; ${ }^{4}$ Division of Physical Therapy, Department of Community and Family Medicine, Duke University Medical Center, Durham, North Carolina 27710, USA; ${ }^{5}$ Department of Pediatrics, Division of Neurology, Duke University School of Medicine, Durham, North Carolina 27710, USA;

${ }^{6}$ Department of Ophthalmology, Duke University School of Medicine, Durham, North Carolina 27710, USA;

${ }^{7}$ Department of Neurobiology, Duke University, Durham, North Carolina 27710, USA
\end{abstract}

[Supplemental material is available for this article.]

\title{
INTRODUCTION
}

Brown-Vialetto-Van Laere syndrome (BVVLS) is a rare and relentlessly progressive neurological disorder, recently identified to be caused by homozygous or compound heterozygous mutations in SLC52A2 and SLC52A3, which encode riboflavin transporter proteins (Green et al. 2010; Johnson et al. 2012). SLC52A2 mutations cause subtype BVVLS2, the cardinal features of which are pontobulbar paralysis resulting in motor weakness and sensory ataxia, sensorineural hearing loss and visual abnormalities due to optic atrophy (Foley et al. 2014).

\footnotetext{
${ }^{8}$ These authors contributed equally to this work.
} 
The age of onset in BVVLS2 varies from infancy to late in the first decade, with progressively worsening symptoms culminating in respiratory insufficiency and death in a few years. By identifying the underlying pathogenic mechanism involved (i.e., reduced transmembrane transport of riboflavin), high-dose riboflavin therapy has been preliminarily reported to result in improvements in the clinical manifestations (Bosch et al. 2012; Foley et al. 2014).

In our previous report (Petrovski et al. 2015) we describe the detection of two SLC52A2 loss-of-function variants in a 20-mo-old girl initially presented with nystagmus and ataxia, followed by the development of flaccid paralysis of the upper arms and weakness of the neck muscles. The diagnosis of BVVLS2 was made within 5 mo of her first symptoms. Riboflavin therapy was instituted immediately upon diagnosis as she was worsening with the development of frequent drooling of saliva and difficulty swallowing. We present in this report the clinical progression of the signs and symptoms over the course of the next 9 mo of therapy with riboflavin, conclusively demonstrating dramatic and continuing improvements in all aspects of the manifestations of this otherwise devastating disorder.

\section{RESULTS}

\section{Treatment Outcomes}

Immediately following the diagnosis, even as CLIA confirmation of the SLC52A2 mutations was pending, we obtained approval of the institutional review board (IRB) at Duke University Medical Center to commence high-dose riboflavin on this patient. This decision was based on the child's rapid neurological deterioration, the fact that a specific treatment for the condition was available and that this treatment (high-dose riboflavin) was not associated with significant toxicity or side effects. After a discussion with the IRB chairwoman and approval of an amendment, we communicated the results to the parents and started treatment within $72 \mathrm{~h}$ of making the diagnosis. Three weeks later, the variants were indeed confirmed by a CLIAcertified laboratory.

Beginning with $10 \mathrm{mg} / \mathrm{kg} / \mathrm{d}$, the prescription was titrated up to the current dose of 70 $\mathrm{mg} / \mathrm{kg} / \mathrm{d}$ over $8 \mathrm{wk}$. Because of the unusually high doses that are being administered, liver and kidney functions are continuing to be closely monitored. Coenzyme Q10 was added $2 \mathrm{mo}$ after diagnosis at a dose of $10 \mathrm{mg} / \mathrm{kg} / \mathrm{d}$, with the intention of presumptively decreasing oxidative stress related to cellular riboflavin deficiency.

The patient has been evaluated in our outpatient clinics every month since the diagnosis by multiple specialists involved in her care. Her progress is charted from the objective findings during these visits, with follow-up assessments by the clinical geneticist, neuro-ophthalmologist, physical therapist, audiologist, and the pediatric neurologists.

\section{Visual Manifestations}

Nystagmus had been the first presenting symptom in our patient at age $15 \mathrm{mo}$. An eye examination and an electroretinogram (ERG) at that time showed a seesaw nystagmus, pale optic nerves suggestive of atrophy and rod-cone dystrophy. Repeat eye examination 6 mo later showed an improvement in the nystagmus and in the optic nerve appearance, with a visual acuity of 20/300. She is currently recognizing colors as appropriate for her age. An ERG has not been repeated because of concerns with sedation.

\section{Hearing}

Our patient has not had any clinical indication of a hearing impairment (bilateral sensorineural hearing loss is commonly seen in young children with BVVLS2, with onset age $\sim 2$ yr). She has been uncooperative with behavioral audiometry, but has had normal otoacoustic 
emissions at the time of diagnosis and 7 mo later. Auditory brainstem evoked response (ABR) testing has not been conducted, because of respiratory concerns related to sedation for the procedure. Speech development has been normal throughout.

\section{Motor Weakness}

At the time of diagnosis, the patient had flaccid paralysis of both upper extremities (Power $0-(\mathrm{VI})$, a head tilt to the right, frequent drooling and difficulty in swallowing of solids. Muscle mass was normal, with no evidence of wasting. In addition to the immediate improvements in drooling, swallowing, and head tilt that were seen in the first 4 wk (described in Petrovski et al. 2015), she has continued to make steady gains in muscle strength. A month after initiation of treatment, she was noticed to have flexion at both elbows (Power II/VI), and minimal movements of her fingers (Power I/VI) (Supplemental Video 1) with still no movement at the shoulders (Power 0/VI). A swallow study at that time showed no abnormalities. Four months after initiation of therapy there was still no movement at the shoulders (Power 0/VI). Frequent flexion of the forearms to $>90^{\circ}$ was observed (Power III/ $\mathrm{VI}$ ) and she was able to grasp objects with some effort (Power II/VI). At 8 mo posttherapy, remarkably, she was able to abduct her upper arms and reach up with her arms outstretched in the air (Power III/VI), twirling both hands (Supplemental Video 2). She had improved flexion at the elbows (Power IV/VI). She was able to pick up and stack four blocks at a time, was able to turn pages in a book and scribble with a pen (Power III/VI). For the first time since the onset of symptoms, knee deep tendon reflexes were elicited, indicative of an improvement in both the sensory and motor axons involved in the reflex arc.

A pretreatment evaluation by a pulmonologist could not be obtained, because of the need to immediately start therapy; 4 mo later, she was found to have a weak cough and a low vital capacity at $51 \%$ of normal, because of weakness of the diaphragm. However, historically, the cough had gotten stronger during this period. Throughout the 9-mo period, the patient's cognitive and social developmental milestones have progressed normally.

\section{Sensory Ataxia}

Before treatment, the patient had an ataxic gait with frequent falls. A month after beginning treatment, the gait had not shown improvements. At 4 mo, the gait was still abnormal, but much steadier than before, indicative of an improvement in the sensory ataxia. At 8 mo, there was minimal unsteadiness and she was able to almost run.

\section{DISCUSSION}

BVVLS2 is a rare example of a neurodegenerative disorder for which a specific therapy has become available after it was discovered that the disease mechanism was due to loss of function in both copies of a riboflavin transporter gene. Foley et al. (2014) described the preliminary response to riboflavin therapy in 16 patients with BVVLS2 who had been diagnosed from 6 mo to several years after onset of symptoms. Improvements in muscle strength were evident in most; improvements in visual evoked potentials and audiometry were demonstrated in one patient. Our patient, the earliest to be treated with riboflavin supplementation after disease onset, has shown a remarkable recovery of muscle strength, improvements in the sensory ataxia and in the ophthalmological findings, with improvements continuing to occur 9 mo after the initiation of treatment. Her hearing has remained normal at an age where it would be expected to be impaired, raising the possibility that the high-dose riboflavin therapy may have forestalled the development of a cardinal manifestation of the 
disorder. Concerns about sedation precluded us from obtaining serial ERG and ABR to monitor her recovery. Because of the discomfort involved and the lack of patient cooperation, we were also unable to obtain an electromyogram/nerve conduction study or detailed pulmonary function tests. Nonetheless, we have incontrovertible evidence demonstrating the remarkable improvements in all areas that were affected prior to treatment.

To our knowledge, our patient is the earliest to be diagnosed with BVVLS2, within 5 mo of onset of symptoms. This early diagnosis made possible by WES enabled the rapid institution of therapy at a critical juncture when she was rapidly deteriorating and also about to receive chemotherapy for a presumed autoimmune encephalopathy. Such early diagnosis has the potential to result in optimal response to riboflavin therapy, likely to be due to the fact that the axonal neuropathy that underlies BVVLS2 is treated before it becomes far advanced, resulting in muscle atrophy. The remarkable recovery of neurological function in our patient is also likely to be related to the very high dose of riboflavin recommended by Dr. A. Reghan Foley, Neuromuscular and Neurogenetic Disorders of Childhood Section, National Institute of Neurological Disorders and Stroke, National Institutes of Health, who shared via personal communication recovery in another BVVLS patient on such a high dose. The exact mechanism by which the high dose crosses over into the cell remains unclear; it is thought that in addition to the overdriving of the other riboflavin transporters encoded by SLC52A3 and SLC52A1, there could also be passive diffusion of the riboflavin into the cells.

Thus far, although reports in the literature have highlighted the potential of WES to change clinical management in the individual patient (Bainbridge et al. 2011; Worthey et al. 2011; Bearden et al. 2014; Fan et al. 2014; Romberg et al. 2014), it is difficult to determine if the benefit is sustained, continually improving or plateauing or if the response was similar in other patients. In our own experience, response to a targeted therapy based on mutations in a specific gene may differ between patients, as was the case in the varying response to quinidine in two of our patients with KCNT1-related epilepsy, compared with a reported case in the literature wherein a dramatic decrease in seizures was noted (Bearden et al. 2014). Factors such as the type of mutation, the length of time that has elapsed before diagnosis and differences in the pharmacodynamics from one patient to the other may influence the therapeutic response in such cases. It is unclear if there would be variability in the degree of responsiveness to riboflavin in other children living with BVVLS2, but we infer from our patient that when a therapeutic response is seen immediately, there is continued improvement with ongoing therapy and that early diagnosis soon after the onset of symptoms may have a role in this favorable therapeutic response.

In conclusion, our follow-up report illustrates the power of WES in enabling a lifesaving and quality of life-improving therapy in a child who otherwise is expected to have had progressive worsening of the disease, potentially resulting in death. She now has the realistic possibility of fully regaining her muscle strength, balance, and vision and leading a productive life, with continued riboflavin therapy.

\section{ADDITIONAL INFORMATION}

\section{Ethics Statement}

The Institutional Review Board of Duke University Medical Center approved this research protocol (Pro00032301). Written informed consent was received from both parents.

\section{Author Contributions}

Patient recruitment and phenotyping: V.S., K.S., M.A.M., L.C., M.A.E-D., and R.K. Writing of manuscript: V.S., S.P., and D.B.G. All authors contributed to reviewing the final draft. 


\section{REFERENCES}

Bainbridge MN, Wiszniewski W, Murdock DR, Friedman J, Gonzaga-Jauregui C, Newsham I, Reid JG, Fink JK, Morgan MB, Gingras MC, et al. 2011. Whole-genome sequencing for optimized patient management. Sci Transl Med 3: 87re3.

Bearden D, Strong A, Ehnot J, DiGiovine M, Dlugos D, Goldberg EM. 2014. Targeted treatment of migrating partial seizures of infancy with quinidine. Ann Neurol 76: 457-461.

Bosch AM, Stroek K, Abeling NG, Waterham HR, ljlst L, Wanders RJ. 2012. The Brown-Vialetto-Van Laere and Fazio Londe syndrome revisited: natural history, genetics, treatment and future perspectives. Orphanet $J$ Rare Dis 7: 83.

Fan Z, Greenwood R, Felix AC, Shiloh-Malawsky Y, Tennison M, Roche M, Crooks K, Weck K, Wilhelmsen K, Berg J, et al. 2014. GCH1 heterozygous mutation identified by whole-exome sequencing as a treatable condition in a patient presenting with progressive spastic paraplegia. J Neurol 261: 622-624.

Foley AR, Menezes MP, Pandraud A, Gonzalez MA, Al-Odaib A, Abrams AJ, Sugano K, Yonezawa A, Manzur AY, Burns J, et al. 2014. Treatable childhood neuronopathy caused by mutations in riboflavin transporter RFVT2. Brain 137: 44-56.

Green P, Wiseman M, Crow YJ, Houlden H, Riphagen S, Lin JP, Raymond FL, Childs AM, Sheridan E, Edwards S, et al. 2010. Brown-Vialetto-Van Laere syndrome, a ponto-bulbar palsy with deafness, is caused by mutations in c20orf54. Am J Hum Genet 86: 485-489.

Johnson JO, Gibbs JR, Megarbane A, Urtizberea JA, Hernandez DG, Foley AR, Arepalli S, Pandraud A, SimónSánchez J, Clayton $P$, et al. 2012. Exome sequencing reveals riboflavin transporter mutations as a cause of motor neuron disease. Brain 135: 2875-2882.

Petrovski S, Shashi V, Petrou S, Schoch K, McSweeney KM, Dhindsa RS, Krueger B, Crimian R, Case L, Khalid R, et al. 2015. Exome sequencing results in successful riboflavin treatment of a rapidly progressive neurological condition. Cold Spring Harb Mol Case Stud 1: a000257.

Romberg N, Al Moussawi K, Nelson-Williams C, Stiegler AL, Loring E, Choi M, Overton J, Meffre E, Khokha MK, Huttner AJ, et al. 2014. Mutation of NLRC4 causes a syndrome of enterocolitis and autoinflammation. Nat Genet 46: 1135-1139.

Worthey EA, Mayer AN, Syverson GD, Helbling D, Bonacci BB, Decker B, Serpe JM, Dasu T, Tschannen MR, Veith RL, et al. 2011. Making a definitive diagnosis: successful clinical application of whole exome sequencing in a child with intractable inflammatory bowel disease. Genet Med 13: 255-262. 


\section{COLD SPRING HARBOR Molecular Case Studies}

\section{Sustained therapeutic response to riboflavin in a child with a progressive neurological condition, diagnosed by whole-exome sequencing}

Vandana Shashi, Slavé Petrovski, Kelly Schoch, et al.

Cold Spring Harb Mol Case Stud 2015, 1: a000265

Access the most recent version at doi: $10.1101 /$ mcs.a000265

$\underset{\text { Material }}{\operatorname{Supplementary}} \quad \underset{1}{\mathrm{http}: / / \text { molecularcasestudies.cshlp.org/content/suppl/2015/06/01/1.1.a000265.DC }}$

References This article cites 10 articles, 1 of which can be accessed free at:

http://molecularcasestudies.cshlp.org/content/1/1/a000265.full.html\#ref-list-1

License This article is distributed under the terms of the Creative Commons Attribution-NonCommercial License, which permits reuse and redistribution, except for commercial purposes, provided that the original author and source are credited.

Email Alerting Receive free email alerts when new articles cite this article - sign up in the box at the Service top right corner of the article or click here. 